RESEARCH ARTICLE

https://doi.org/10.17059/ekon.reg.2021-4-9

UDC code: $332.1: 519.8: 614.2$

JEL codes: C44, C31, R15, I15 (cc) BY 4.0

Alicja Olejnik ${ }^{\text {a) }}$, Agata Żółtaszek ${ }^{\text {b) }}$, Jakub Olejnik c)

a, b, c) University of Lodz, Lodz, Poland

a) e-mail: alicja.olejnik@uni.lodz.pl

\title{
Spatial Solution to Measure Regional Efficiency - Introducing Spatial Data Envelopment Analysis ${ }^{1}$
}

When investigating healthcare efficiency at the regional level, the problem of interactions between neighbouring locations arises. The health of the population in a given region is related to the healthcare in other areas through a medical tourism, a limited number of highly specialised institutions, competition between institutions, etc. Ignoring these inter-regional links may result in a systematic bias in the efficiency analysis. Similar issues may hinder any regional studies. Hence, the main purpose of this paper is to introduce a new approach to measuring efficiency in regional studies through spatial data envelopment analysis (SDEA). The paper offers a proper mathematical formulation of the new methodology and highlights differences between classic data envelopment analysis (DEA) and the newly developed method. The motivation for seeking a new solution to the problem of spatially adequate assessment of regional efficiency is derived from the literature review and a discussion of the presented theoretical examples. The classic DEA allows for multidimensional analysis of the performance of homogenous independent decision-making units. However, in regional studies, an area where DEA has gained popularity, the assumption of the isolation of decision-making units seems to be unfounded. In the SDEA approach, the region-specific spatial context is incorporated into the analysis via the $W$ matrix and spatial interactions are reflected in the model through spatially weighted inputs and outputs. Therefore, in our paper, we verify the hypothesis that spatial interactions are an indispensable factor of regional efficiency analysis. A study of healthcare efficiency in European regions is presented as an illustration of the utility of the new methodology. Furthermore, we compare the results of the classic DEA approach with those of the SDEA, which is augmented with the spatial equivalents of inputs and outputs. Our results suggest that classic DEA undervalues regional healthcare efficiency by underestimating the region-specific spatial context. ${ }^{2}$ Researchers may find the introduced SDEA method useful in all space related fields when investigated phenomenon exhibits spatial autocorrelation. In particular, the new approach may deepen the regional efficiency analysis of innovation, development, logistics, tourism, etc.

Keywords: regional science, economics, data envelopment analysis, spatial data envelopment analysis, regional efficiency, spatial economy, spatial interactions, healthcare, healthcare efficiency, diseases of affluence

\section{Acknowledgements}

The authors would like to thank Dr Amanda Fitzgibbons of Edanz Group (www.edanzediting.com/ac) for editing a draft of this manuscript.

For citation: Olejnik, A., Żółtaszek, A. \& Olejnik, J. (2021). Spatial Solution to Measure Regional Efficiency - Introducing Spatial Data Envelopment Analysis. Ekonomika regiona [Economy of regions], 17(4), 1166-1180, https://doi.org/10.17059/ ekon.reg.2021-4-9

\footnotetext{
${ }^{1}$ (c) Olejnik A., Żółtaszek A., Olejnik J. Text. 2021.

${ }^{2}$ Some of the preliminary results were presented at the 59th ERSA Congress: Cities, regions and digital transformations: opportunities, risks and challenges, 2019, Lyon, and in a working paper.
} 


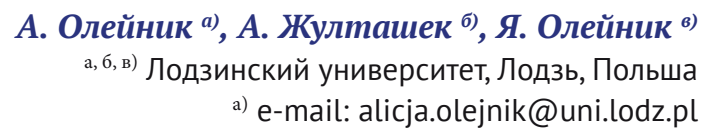

\section{Применение методики анализа охвата пространственных данных для измерения региональной эффективности}

При исследовании эффективности здравоохранения на региональном уровне возникает проблема взаимодействия соседних территорий. Здоровье населения в конкретном регионе также зависит от системы здравоохранения в других областях, поскольку необходимо учитывать такие факторы, как медицинский туризм, ограниченное количество узкоспециализированных учреждений, конкуренция между учреждениями и т. д. Игнорирование подобных межрегиональных связей может привести к возникновению систематической погрешности в процессе анализа эффективности. Такие проблемы могут помешать проведению региональных исследований. Цель данной статьи - представить новый подход к измерению региональной эффективности с помощью анализа охвата пространственных данных (SDEA). Предложена математическая формулировка новой методологии и описаны различия между классическим анализом охвата данных (DEA) и разработанным подходом. Обзор литературы и теоретических примеров продемонстрировал необходимость поиска нового решения проблемы оценки региональной эффективности с учетом пространственного компонента. Классический метод позволяет проводить многомерный анализ производительности однородных независимых центров принятия решения. Однако в региональных исследованиях, где подход DEA приобрел популярность, предположение об изолированности центров принятия решения кажется необоснованным. В то же время анализ охвата пространственных данных исследует специфичный для региона пространственный контекст с помощью матрицы W. Также в данной модели пространственные взаимодействия выражаются через пространственно взвешенные входные и выходные данные. В статье была проверена гипотеза о важности фактора пространственных взаимодействий в контексте анализа региональной эффективности. Исследование эффективности здравоохранения в европейских регионах продемонстрировало практическую ценность новой методологии. Сравнение результатов двух моделей показало, что классический анализ охвата данных недооценивает региональную эффективность здравоохранения, не принимая во внимание региональный пространственный контекст. Представленная методика может использоваться в любых пространственных исследованиях в случае наличия пространственной автокорреляции. В частности, новый подход может быть использован для углубленного анализа эффективности инноваций, развития, логистики, туризма на региональном уровне.

Ключевые слова: региональная наука, экономика, анализ охвата данных, анализ охвата пространственных данных, региональная эффективность, пространственная экономика, пространственные взаимодействия, здравоохранение, эффективность здравоохранения, болезни изобилия

\section{Благодарность}

Авторы выражают благодарность доктору Аманде Фитигиббонс из Edanz Group (www.edanzediting.com/ac) за редактирование черновика этой статьи.

Для цитирования: Олейник А., Жулташек А., Олейник Я. Применение методики анализа охвата пространственных данных для измерения региональной эффективности // Экономика региона. 2021. Т. 17, вып. 4. С. 1166-1180. https://doi. org/10.17059/ekon.reg.2021-4-9.

\section{Introduction}

Data envelopment analysis (DEA) was introduced in 1978 by Charnes, Cooper, and Rhodes [1]. It is an optimisation-based method of analysing the relative efficiency of homogeneous but independent decision-making units (DMUs). In this approach, efficiency or productivity is measured by a ratio of weighted outputs to weighted inputs, without specifying an explicit functional relation between them. DEA is based on the economic concept of the production function, although the struc- tural parameters are not being estimated. In fact, the original aim of DEA and the related efficiency measure was not to describe the theoretical function but rather to support managerial assessment and decision-making at the micro-level. Thus, following the introduction of the original DEA, the DMUs considered initially were typically small economic entities, such as companies, schools, and programmes $[1,2,3]$. In more recent literature, the term production is not necessarily used in its literal sense and it is commonly used more broadly 
in general economics. Examples of research areas that use the DEA methodology include:

- health economics, for assessing efficiency of healthcare $[4,5]$,

- public safety, to rate the efficiency of police in relation to crime rates [6-8],

- environmental and energy economics, for decision-making and policy assessment (extensively reviewed by Mardani et al. [9]) and sustainable development [10],

- logistics [11-14], and

- tourism [15].

We note that not only has a thematic expansion of the theory of production been observed but also, simultaneously, there has been a change in the perception of what a DMU can be. Such units no longer have to be distinct, independent companies (i.e., typical micro-level economic entities). In fact, much smaller objects (e.g., flight routes, sub-units) can be assessed provided that if the relevant decisions are made at a higher (e.g., company) level, they are managed separately for nano-level decision-making $[16,17]$. Furthermore, mezzo (or macro) units become increasingly frequent subjects of research using the DEA methodology. In particular, in the field of regional science, regions can be viewed as DMUs that operate with limited resources and aim to maximise a set of tangible effects. As a result, the DEA methodology has become popular in this field. For example, the DEA approach has been used in research on regional inequality in planning infrastructure and human capital development $[12,18]$ and in investigations of social and economic disadvantage (e.g. [19]). Wang and Feng [20] used DEA to assess productivity and economic growth in Chinese regions and a DEA study of the efficiency of the Italian regions was conducted by Suzuki, Nijkamp and Rietveld [15] to assess the tourism policies of tourist destinations.

Combining DEA results with geographic information systems (GIS) enhances the investigative power of spatial pattern analyses. Kapfer et al. [21] used this approach to compare the productivity of agricultural land plots. Lao and Liu [22] studied the Californian bus line system by profiling demographics using GIS and then calculating the efficiency of public transit agencies using DEA. Almeida et al. [23] applied DEA-GIS tactics to measure the attractiveness of the Osasco region in Sao Paulo, Brazil to businesses before and after the opening of Rodoanel, a major highway. Kourtit and Nijkamp [24] performed a multi-step DEAGIS analysis of creative high-tech companies in the Netherlands, based on their geographical locations and regional efficiency.
Typically, regional studies, including the above papers, treat regions as separate and independent DMUs, which is in line with DEA assumptions. While some conclusions about the existence of spatial patterns are offered, they are not confirmed statistically. Therefore, to verify their hypotheses, some researchers apply exploratory spatial data analysis (ESDA) to the results of the standard DEA as a subsequent step. Angeriz, McCombie and Roberts [25] analysed the efficiency of manufacturing in 68 European Nomenclature des Unités Territoriales Statistiques (NUTS) 1 regions using DEA and then tested the efficiency coefficients for spatial autocorrelation (local and global) to verify spatial patterns. Similarly, Wang, Jin and Zhou [26] used DEA-ESDA to examine grain production in 172 counties in the Hebei Province of China for the period 1990-2005. Mokaddem [27] examined economic development across 252 Tunisian delegations and applied not only spatial statistics, but also a spatial econometric model to explain DEA efficiency. Spatial econometrics was also used by Schaffer, Simar and Rauland [28], who made an attempt to model DEA efficiency coefficients using a spatial geoadditive regression. Both Mokaddem [27] and Schaffer, Simar and Rauland [28] incorporated a spatial weight matrix $\mathbf{W}$ to describe the spatial interactions in the post-DEA analysis. Maté-Sánchez-Val and Madrid-Guijarro [29] used this approach in reverse: they introduced a spatial weight matrix in the pre-DEA stage of their study concerning the productivity of small and medium enterprises. Their modification of the DEA methodology assumed that each DMU should be compared only with the neighbouring units, as recognised by the $\mathbf{W}$ matrix. Although this is an interesting approach, it can be effectively employed only if a given unit has a sufficiently large number of neighbours to enable the local production possibility set to be adequately identified.

Our contribution is the introduction of explicit spatial interactions into the DEA model, incorporated through the spatial weight matrix $\mathbf{W}$. As usual, matrix $\mathbf{W}$ is a given a priori as an $N \times N$ spatial weight matrix, which represents the spatial structure of observations. The elements $w_{i j}$ of $\mathbf{W}$ are valued at one $\left(w_{i j}=1\right)$ if the locations $i$ and $j$ are neighbours and all other elements, in particular, the diagonal ones, are zero. Therefore, the neighbourhood structure is represented by the spatial weight matrix $\mathbf{W}$. We consider the most common weight matrices in regional science, namely those in which a neighbourhood is based on distance relationship or contiguity [30].

The structure of spatial interactions (represented by the $\mathbf{W}$ matrix) should be included di- 
rectly in the efficiency analysis, as the relationship between effects in one region and inputs in another region is an integral part of the production process. For example, higher expenditure on research and development in neighbouring regions can influence a region's own level of innovativeness through grants, universities, and general knowledge spillovers [31]. A technological advancement in medical equipment or human capital (treated as an input) may result in a healthier population (the output) not only in a given region, but also in neighbouring regions [32, 33, 34]. Conversely, the production outputs of neighbouring regions may be achieved partly through the production processes in a given region. For instance, environmental indicators, which can be a direct output or a production by-product and are not bounded within administrative borders, can have positive or negative consequences simultaneously within a region and in its neighbouring regions. Moreover, the output of one region can become the input of a neighbouring region. For example, when DEA is used to measure the efficiency of regional development (based on gross domestic product (GDP) as the main output), the spatial spillover effect indicates that a region with a high level of GDP may stimulate the development of its neighbouring regions.

The remainder of the paper is structured as follows. Section 2 introduces the methodology, providing a tool for frontier analysis that takes into account spatial autocorrelation. Section 3 illustrates the methodology by applying it to an analysis of the efficiency of healthcare in European regions. A discussion of the empirical results obtained is also included in Section 3. Finally, conclusions are outlined in Section 4.

\section{Methodology}

In this section, we present the spatial data envelopment analysis (SDEA) methodology as an extension of the standard DEA framework. First, let us introduce some notation. We assume that $S$-element vectors $\mathbf{x}_{i}$, for $i \leq n$, describe the values of inputs available for each individual unit $i=1, \ldots, n$. Similarly, the $M$-element vectors $\mathbf{y}_{i}$, for $i \leq n$, contain outputs produced by each unit. Additionally, we will use the matrices $\mathbf{X}=\left[\mathbf{x}_{1}, \ldots, \mathbf{x}_{n}\right]$ and $\mathbf{Y}=\left[\mathbf{y}_{1}, \ldots, \mathbf{y}_{n}\right]$ of combined inputs and outputs, respectively.

Let us start with the Charnes, Cooper, and Rhodes (CCR) [1] model, in which the efficiency $\theta_{k}$ of a unit $k \in\{1, \ldots, n\}$ is described by the optimal value for the following non-linear programme:

$$
\text { maximise } \theta_{k}(u, v)=\frac{u^{T} y_{k}}{v^{T} x_{k}},
$$

$$
\theta_{i}(u, v) \leq 1, i \in\{1, \ldots, n\}, 0 \leq u \in \mathbb{R}^{M}, 0 \leq v \in \mathbb{R}^{S} .
$$

Thus, the relative efficiency is the ratio of the value of outputs to the value of inputs with respect to optimal prices $(u, v)$. However, a solution to programme (1) is typically obtained by solving a computationally simpler linear programme, as shown in (2) and (3). Namely, it is easily observed that the objective function in (1) is invariant when variables $(u, v)$ are multiplied by a non-zero constant. Thus, we may restrict the feasible set so that the value of the denominator $v^{T} \mathbf{X}_{k}$ does not exceed one. Then, it can be observed that for an optimal $v$, we actually have $v^{T} \mathbf{X}_{k}=1$. In this way, we obtain an equivalent formulation of (1) in the so-called input-oriented form:

$$
\begin{gathered}
\text { maximise } \theta_{k}={ }^{k} \\
v^{T} \mathbf{x}_{k} \leq 1, \mathbf{Y} u \leq \mathbf{X} v, 0 \leq u, v .
\end{gathered}
$$

The following linear programme (3), dual ${ }^{1}$ to (2), reveals the connection of the efficiency coefficient $\theta_{k}$ to the well-known Farrell efficiency measure [35]:

$$
\begin{gathered}
\text { minimise } \theta_{k}, \\
\mathbf{X} \lambda \leq \theta_{k} \mathbf{x}_{k}, \mathbf{Y} \lambda \leq \mathbf{y}_{k}, 0 \leq \lambda \in \mathbb{R}^{n} .
\end{gathered}
$$

Notice that the production possibility set $\wp$ is exactly the feasible region in (3). In addition, notice that the value of $\theta_{k}$ in (3) is the coefficient by which inputs $\mathbf{x}_{k}$ for the $k$-th unit can be uniformly decreased so that the point $\left(\theta_{k}, \mathbf{x}_{k}, \mathbf{y}_{k}\right)$ still lies within the (constant returns to scale) positive cone generated by vectors $\left(\mathbf{x}_{i}, \mathbf{y}_{i}\right), i=1, \ldots, n$. Thus, the optimal $\theta_{k}^{*}$ is Farrell's efficiency measure. Alternatively, (1) can be transformed by the constraint $u^{T} \mathbf{y}_{k} \geq 1$, in which case it takes an obvious reciprocity of the objective function that one obtains using the output-oriented models (2') and (3'):

$$
\begin{gathered}
\text { minimise } \breve{\theta}_{k}=v^{T} \mathbf{x}_{k}, \\
u^{T} \mathbf{y}_{k} \geq 1, u^{T} \mathbf{Y} \geq v^{T} \mathbf{X}, 0 \leq u, v . \\
\operatorname{maximise} \breve{\theta}_{k}, \\
\mathbf{X} \lambda \leq \mathbf{x}_{k}, \mathbf{Y} \lambda \geq \breve{\theta}_{k} \mathbf{y}_{k}, 0 \leq \lambda .
\end{gathered}
$$

Also notice that a comparison of (3) and (3') reveals that $\breve{\theta}_{k}^{*}=\frac{1}{\theta_{k}^{*}}$.

The contribution of the original paper by Charnes, Cooper and Rhodes [1] was not a mere presentation of problem (1) as a dual to (3) or (3'). In fact, the CCR model introduced a refined concept of efficiency compared with the Farrell efficiency measure.

\footnotetext{
${ }^{1}$ Duality of linear programs is a well-established term in operational research. For more refer to [36].
} 
The above models assume that it is possible to scale any point in the production possibility set by an arbitrary factor. In other words, the assumption of constant returns to scale is incorporated into the programme with the condition that the set $\wp$ is a positive cone. Subsequently, the Banker, Charnes, and Cooper model removed the assumption of constant returns to scale [3]. Instead, the feasible points are those that are convex combinations of data points. Thus, the relevant programme takes the form below:

$$
\begin{gathered}
\text { minimise } \theta_{k}, \\
\mathbf{X} \lambda \leq \theta_{k} \mathbf{x}_{k}, \mathbf{Y} \lambda \leq \mathbf{y}_{k}, \lambda^{T} \mathbf{1}=1,0 \leq \lambda \in \mathbb{R}^{n} .
\end{gathered}
$$

Now, we turn to the spatial setting. First, however, let us fix a spatial weight matrix $\mathbf{W}=\left[w_{i j}\right]_{i j \leq n}$ and let vectors $\mathbf{x}_{i}=\left(x_{i s}\right)_{s \leq S}$ and $\mathbf{y}_{i}=\left(y_{i k}\right)_{m \leq M}, i \leq n$ be defined as previously. To incorporate spatial interaction into the evaluation of unit efficiency, we assume that the spatial interaction occurs through three parallel channels of influence. The first channel concerns the spatial relevance of inputs. More specifically, a subset $V \subset\{1, \ldots, S\}$ of input variables in a region (called spatial inputs) affects the overall level of outputs in the neighbouring regions. Second, to account for the relevance of spatial spillovers to outputs, we assume that there is a distinguished subset $Q \subset\{1, \ldots, M\}$ of output variables (spatial product inputs) that also affects the overall level of outputs in the neighbouring regions. Third, there is a subset $P \subset\{1, \ldots, M\}$, $P \cap Q=\varnothing$ of output variables in the neighbouring regions (spatial outputs) that are influenced by the level of inputs in the given unit. Finally, we define the efficiency measure of a spatial unit $i \leq n$ as the optimal value of the following programme:

$$
\begin{aligned}
& \max \operatorname{imise} \theta_{k}\left(\mu_{k m}, v_{k s}, \eta_{k m}, \omega_{k s}\right):= \\
& \frac{\sum_{m=1}^{M} \mu_{k m} y_{k m}+\sum_{m \in P} \eta_{k m} \sum_{i=1}^{n} w_{k i} y_{i m}}{\sum_{s=1}^{S} v_{k s} x_{k s}+\sum_{s \in V} \omega_{k s} \sum_{i=1}^{n} w_{k i} x_{i s}+\sum_{m \in Q} \eta_{k m} \sum_{i=1}^{n} w_{k i} y_{i m}},
\end{aligned}
$$

with the restriction that:

$$
\frac{\sum_{m=1}^{M} \mu_{k m} y_{j m}+\sum_{m \in P} \eta_{k m} \sum_{i=1}^{n} w_{j i} y_{i m}}{\sum_{s=1}^{S} v_{k s} x_{j s}+\sum_{s \in V} \omega_{k s} \sum_{i=1}^{n} w_{j i} x_{i s}+\sum_{m \in Q} \eta_{k m} \sum_{i=1}^{n} w_{j i} y_{i m}} \leq 1,
$$

for all $j=1, \ldots, n$ and assuming that the multipliers $\mu_{k m}, v_{k s}, \eta_{k m}$, and $\omega_{k s}$ are non-negative.

Definition 1. Spatial unit $k$ is Farrell efficient if $\theta_{k}^{*}=1$ for the optimal value of programme (5).

Definition 2. Spatial unit $k$ is CCR-efficient if the following two conditions hold: (a) unit $k$ is Farrell efficient, and (b) for an optimal solution of
(5), the values of the variables $\mu_{k m}^{*}$ for $m \leq M$ and $\eta_{k m}^{*}$ for $m \in P$ are positive.

Our spatial modification allows spatial variables to be introduced into the DEA approach in three ways. First, if the production process is not bound within administrative borders and some outputs are generated or observed in neighbouring regions, we include spatial outputs (via $\left.\sum_{m \in P} \eta_{k m} \sum_{i=1}^{n} w_{k i} y_{i m}\right)$ in the numerator of (5). Second, if outputs in a given region are affected by some inputs in neighbouring regions, we add spatial inputs $\left(\sum_{s \in V} \omega_{k s} \sum_{i=1}^{n} w_{i i} x_{i s}\right)$ to the denominator. In these ways, we can ensure that selected neighbouring inputs and outputs, as well as the region's own inputs and outputs, are included in the DEA. In some cases, outputs (products) in one region can be perceived as inputs in another. Therefore, the third way of incorporating spatial interactions is to include spatially weighted outputs corresponding to the region's own inputs; these spatial product inputs are included through $\sum_{m \in Q} \eta_{k m} \sum_{i=1}^{n} w_{j i} y_{i m}$ in the denominator. We emphasise that not all inputs and outputs have to interact spatially. Therefore, not all of the spatial variables have to be included in the linear programming problem. Selection of spatial variables and their role in an SDEA model depends on the nature of the production process, theoretical assumptions, and the results of conducted ESDA.

For preliminary analysis of potential spatial variables as well as the post-DEA verification of efficiency patterns, the most useful spatial tools are Moran's I statistics and tests. In our study, we employed uni- and bivariate statistics at the local and global levels [37, 38]. The local Moran's $I_{i}$ indicates whether the $i$-th territory is surrounded by locations with similar (positive spatial autocorrelation) or dissimilar values (negative spatial autocorrelation). This local statistic takes the following form:

$$
I_{i}=\frac{N^{2}}{\sum_{i=1}^{N} \sum_{j=1}^{N} w_{i j}} \frac{\left(x_{i}-\bar{x}\right) \sum_{j=1}^{N} w_{i j}\left(x_{j}-\bar{x}\right)}{\sum_{k=1}^{N}\left(x_{k}-\bar{x}\right)^{2}},
$$

where $x_{i}$ represents the variable in question, $\overline{\boldsymbol{x}}$ is its mean and $w_{i j}$ is an element of $\mathbf{W}$, which is the spatial weight matrix. This local statistic is a base for the local indicators of spatial association (LISA), which allows for the classification of regions into high-high (hot-spot) and low-low (cold-spot) spatial clusters, as well as identification of the high- 
low and low-high spatial outliers. Additionally, the reference to high and low is relative to the mean of the variable, and should not be interpreted in an absolute sense [37].

To assess the existence of a spatial association, the global Moran's $I$ is used. It measures overall regional similarity for all locations as a mean of local $I_{i}$ :

$$
I=\frac{N}{\sum_{i=1}^{N} \sum_{j=1}^{N} w_{i j}} \frac{\sum_{i=1}^{N} \sum_{j=1}^{N} w_{i j}\left(x_{i}-\bar{x}\right)\left(x_{j}-\bar{x}\right)}{\sum_{i=1}^{N}\left(x_{i}-\bar{x}\right)^{2}},
$$

using the notation of equation (6). It identifies positive spatial autocorrelation if: $I>-\frac{1}{N-1}$ (i. e. on average each region is surrounded by locations with similar values of $x$ ) and negative spatial autocorrelation otherwise (significantly different values of $x$ in close proximity).

The concept of spatial autocorrelation can be generalised to the spatial correlation between two variables. Bivariate Moran's I measures the average association of $y$-value in a given location with the values of another variable $(x)$ in nearby areas. Assuming that, we have:

$$
I=\frac{N}{\sum_{i=1}^{N} \sum_{j=1}^{N} w_{i j}} \frac{\sum_{i=1}^{N} \sum_{j=1}^{N} w_{i j}\left(x_{i}-\bar{x}\right)\left(y_{j}-\bar{y}\right)}{\sum_{j=1}^{N}\left(x_{j}-\bar{x}\right)^{2}} .
$$

The weight matrix is an essential element of any spatial data analysis, including SDEA and ESDA, and as such, it gained a considerable attention [30] and remains the cause of disputes over how it should be specified. The research conducted in this paper is based on NUTS 2 regions, some of which cover a great geographical area that is sparsely populated (e. g. North and East Finland), and adversely, some are very small and densely populated (e.g. Inner London). Therefore, it seems to be better justified to apply the contiguity weight matrix, in which regions are considered to be neighbours when sharing a boundary, then distance-based weight matrices. Consequently, in the study, the contiguity weight matrix was chosen for the analysis.

\section{Results based on application of SDEA to healthcare in EU regions}

To illustrate our methodology, we use SDEA to consider the efficiency of healthcare in European regions. There is no doubt that economic growth entails not just environmental but also health concerns, with the diseases of affluence becoming an increasingly urgent issue. A variety of cardiovascular diseases, respiratory system diseases (e. g., asthma), obesity and its consequences (e.g., diabetes), addictions and other mental problems, and cancers are serious issues, as discussed in a number of World Health Organiwation (WHO) reports. ${ }^{1}$ In general, there are high levels of healthcare funding and expenditure on the prevention and treatment of these 'Western diseases' in the Western countries because they are an economic concern in rich, developed countries. Therefore, it is worthwhile searching for appropriate tools to examine the prevalence and efficiency of healthcare systems that can assist in reducing the unwanted consequences of wealth. [32-34, 39-43].

All data used in the analysis below are taken from the Eurostat database. The data cover 282 regions of the European Union, Norway, Switzerland, and Luxemburg for the years 20132015 . The inputs are the number of medical doctors (DOC), number of hospital beds (BED), and financial recourse, represented by regional GDP. Data descriptions and basic statistics are provided in Table 1 . On average, there were 350 doctors and 507 beds per 100,000 inhabitants in each European region with the GDP per capita of 27,029 Euro. The number of doctors was the highest in Greek, Czech, and Austrian regions and the lowest in Polish and Dutch locations. The number of beds was the highest in Germany and exceeded the minimal values for Greece and Spain almost eight times. For GDP, the lowest values were reported in Bulgaria and Hungary and the unique maximal value was observed in Inner London-West. Moreover, all resources are all positively spatially correlated.

The outputs are measured using the mortality rates for six chosen Western diseases, namely diabetes mellitus (D), mental and behavioural disorders $(\mathrm{M})$, diseases of the nervous system and the sense organs (NS), diseases of the circulatory system $(\mathrm{C})$, diseases of the respiratory system $(\mathrm{R})$, and neoplasms $(\mathrm{N})$. Age-standardised death rates are measured by the region of residence (at the NUTS

\footnotetext{
${ }^{1}$ WHO Report: ATLAS on Substance Use (2010). Chapter 1: Psychoactive substance use: Epidemiology and burden of disease. Retrieved from: http://www.who.int/substance_abuse/ publications/treatment/en/ (Date of access: 25.06.2016); WHO Report: Global Status Report on Noncommunicable Diseases 2010 (2011). Retrieved from: http://www.who.int/nmh/publications/ncd_report2010/en/ (Date of access: 25.06.2016); WHO Report: Global Report on Urban Health (2016). Retrieved from: http://www.who.int/kobe_centre/publications/urban-global-report/en/ (Date of access: 25.06.2016).
} 
Table 1

Basic statistics for input variables

\begin{tabular}{|l|c|c|c|c|c|c|}
\hline \multicolumn{1}{|c|}{ Disease } & Mean & Std. dev. & Min & Max & Moran's I & Pseudo $\boldsymbol{p}$-value \\
\hline $\begin{array}{l}\text { Medical doctors per 100,000 inhabitants } \\
\text { by NUTS 2 regions }\end{array}$ & 350 & 98 & 132 & 867 & 0.33 & $<0.001$ \\
\hline $\begin{array}{l}\text { Available hospital beds per 100,000 } \\
\text { inhabitants by NUTS 2 regions }\end{array}$ & 507 & 217 & 164 & 1,290 & 0.73 & $<0.001$ \\
\hline $\begin{array}{l}\text { GDP at current market prices by } \\
\text { NUTS 2 regions in purchasing power } \\
\text { standards per inhabitant }\end{array}$ & 27,029 & 13,121 & 7,700 & 158,80 & 0.32 & $<0.001$ \\
\hline
\end{tabular}

Source: own compilation.

Table 2

Basic statistics for mortality rates from Western diseases

\begin{tabular}{|l|c|c|c|c|c|c|}
\hline \multicolumn{1}{|c|}{ Disease } & Mean & Std. dev. & Min & Max & Moran's I & Pseudo $\boldsymbol{p}$-value \\
\hline Diabetes mellitus & 21.96 & 11.02 & 5.13 & 69.18 & 0.64 & $<0.001$ \\
\hline Mental and behavioural disorders & 41.72 & 26.16 & 0.19 & 101.61 & 0.85 & $<0.001$ \\
\hline $\begin{array}{l}\text { Diseases of the nervous system } \\
\text { and the sense organs }\end{array}$ & 39.359 & 19.422 & 10.52 & 162.97 & 0.83 & $<0.001$ \\
\hline Diseases of the circulatory system & 402.8 & 206.87 & 162.96 & 1225.61 & 0.93 & $<0.001$ \\
\hline Diseases of the respiratory system & 85.525 & 30.581 & 31.56 & 174.34 & 0.81 & $<0.001$ \\
\hline Neoplasms & 269.67 & 31.666 & 210.84 & 374.51 & 0.70 & $<0.001$ \\
\hline
\end{tabular}

Source: own compilation.

2 level) as 3-year averages using 2013, 2014 and 2015.

The only available statistics on the prevalence of diseases are mortality rates. It should be noted that these statistics are not ideal because we do not know how many people are actually ill or diagnosed with each disease, or how many of the ill die because of the disease in question rather than other causes. Moreover, the mortality rate as a statistical measure refers to the region in which the patient died, which may be different to the one in which they lived. This means that death rate statistics for regions with highly specialised clinics may be artificially inflated, which may distort the results of the efficiency analysis in some regions. Bearing these issues in mind, there are no reliable widespread statistics on disease prevalence available for the NUTS 2 regions, so the data used are the best available. Additionally, no standardised annual mortality rates are available in Eurostat. The available 3-year averages, on the one hand, reduce the possibility of comparing the prevalence and efficiency in subsequent years, while, on the other, eliminate possible outliers.

Table 2 presents the basic statistics for mortality rates for the six Western diseases on which we focus. The leading causes of death are the dis-

\footnotetext{
${ }^{1}$ Report of Eurostat's Task Force: Revision of the European Standard Population 2013. Retrieved from: http://ec.europa. eu/eurostat/documents/3859598/5926869/KS-RA-13-028-EN. PDF/e713fa79-1add-44e8-b23d-5e8fa09b3f8f (Date of access: 25.06.2016).
}

eases of the circulatory system and neoplasms. The highest dispersion can be observed for mental and behavioural disorders as the relative deviation exceeds $63 \%$ and the mortality rate is over 500 times higher in some UK regions than in territories with the lowest values in Poland, Bulgaria, and Romania. Moreover, all death rates for selected diseases are highly and positively spatially correlated. In particular, for diseases of the circulatory system, Moran's I is as high as 0.93 .

First, the six Western diseases described above and three healthcare input variables were used to calculate efficiency using the classic DEA approach. As the outputs are defined as mortality rates, we have calculated the "survival" rates that are the complement of death rates (both sum to 100,000). Figure 1 presents the efficiency coefficients for standard DEA on a choropleth map, and shows identified clusters and outliers on LISA map. It can be seen that very few of the regions dispersed across Bulgaria, Romania, Portugal, Greece and Luxemburg have fully efficient healthcare systems. Generally, higher performance can be observed in Eastern Europe, especially the Balkans, the United Kingdom, as well as southern Italy and Spain. Germany has the least efficient system and unused input excess of 50$60 \%$. In fact, Figure 1 indicates the existence of a large cluster of low-efficiency regions located in Germany and its neighbours, Austria, France, Slovakia and the Czech Republic. A large group of high performing regions is located in the Balkans, 


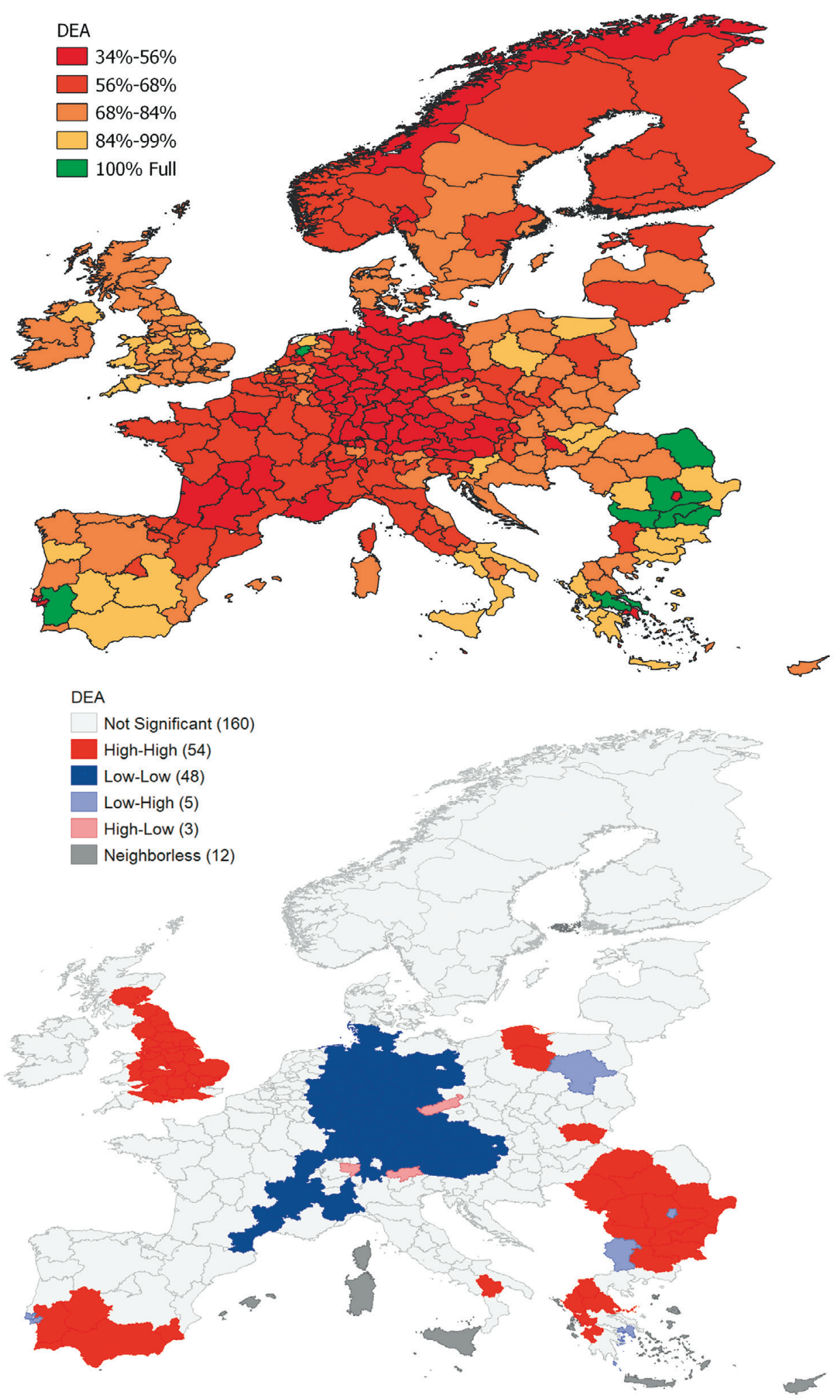

Fig. 1. Classic DEA efficiency coefficient and LISA analysis of healthcare systems, NUTS 2, 2013-2015, by deciles

southern Iberian Peninsula, the United Kingdom, and northern Poland. The global autocorrelation is high with Moran's I $=0.6(p<0.001)$.

An analogous analysis can be conducted using the newly developed SDEA approach. This setting enables the inclusion of potential spillovers across the regions on both the input and output sides in the evaluation of healthcare systems.

In this analysis, six additional spatially weighted outputs and three spatially weighted inputs (with the chosen contiguity weight matrix) were introduced into the model. The preliminary 
Table 3

Bivariate Moran's I statistics for outputs with spatially weighted inputs

\begin{tabular}{|c|c|c|c|}
\hline WX & $\mathbf{Y}$ & Bivariate Moran's I & $\begin{array}{c}\text { (Pseudo } \text {-value) } \\
\text { significance }\end{array}$ \\
\hline BED & $\mathrm{D}$ & 0.28 & 0.001 \\
\hline BED & $\mathrm{M}$ & -0.20 & 0.001 \\
\hline BED & $\mathrm{NS}$ & -0.17 & 0.001 \\
\hline BED & $\mathrm{R}$ & -0.40 & 0.001 \\
\hline BED & $\mathrm{C}$ & 0.21 & 0.001 \\
\hline BED & $\mathrm{N}$ & -0.047 & 0.05 \\
\hline DOC & $\mathrm{D}$ & 0.18 & 0.001 \\
\hline DOC & $\mathrm{M}$ & -0.16 & 0.001 \\
\hline DOC & $\mathrm{NS}$ & -0.63 & 0.001 \\
\hline DOC & $\mathrm{R}$ & -0.19 & 0.001 \\
\hline DOC & $\mathrm{C}$ & -0.027 & 0.18 \\
\hline DOC & $\mathrm{N}$ & -0.18 & 0.001 \\
\hline GDP & $\mathrm{D}$ & 0.04 & 0.081 \\
\hline GDP & $\mathrm{M}$ & 0.18 & 0.001 \\
\hline GDP & $\mathrm{NS}$ & 0.06 & 0.048 \\
\hline GDP & $\mathrm{R}$ & -0.038 & 0.100 \\
\hline GDP & $\mathrm{C}$ & 0.11 & 0.001 \\
\hline GDP & $\mathrm{N}$ & 0.015 & 0.310 \\
\hline
\end{tabular}

Source: own compilation.

results confirmed the correlation between inputs and outputs measured by Neyman-Pearson correlation coefficient. Further research showed spatial autocorrelation of outputs, measured by Moran's I statistics, as well as correlation between outputs and spatial lags of the input variables, without inherent correlation, verified using the bivariate Moran's I.

The assumption of spatial interactions between the variables seems to be fully justified (see Table 3). First, the negative sign of the Moran's I statistics suggests that the number of medical doctors and hospital beds in neighbouring regions decrease the death rates caused by most of the analysed diseases. This may be due to patients travelling for surgery or treatment to highly specialised clinics located in nearby regions.

The exception to this tendency is diabetes for which prosperity, also represented indirectly by i.a. the number of doctors and hospital beds in neighbouring regions, increases risk factors leading to the growth of mortality, expressed by a positive sign of Moran's I. The same applies to the cardiovascular diseases. Moreover, high prevalence and mortality of a disease in a given territory (region, group of them, or a whole country) can lead to the creation of new specialist healthcare centres dedicated to the treatment of that particular conditions.

In the case of GDP, bivariate correlations are positive. GDP is perceived as the measure of re- gional development and prosperity, and as such, it may stimulate the mortality from diseases of affluence in the wider territory, including at bordering locations. Therefore, it confirms the negative impact of wealth on public health.

It can also be seen that not every single spatially weighted input is spatially correlated with every single output, i.e. on average, the number of doctors in one region does not impact the number of deaths caused by the diseases of the circulatory system in neighbouring regions. Similarly, regional GDP does not affect the surrounding cases of the respiratory system and neoplasms. This is the case for only three relations and does not affect the results of the analysis as in both DEA and SDEA inputs constitute a compact set, and technically it is not possible to eliminate individual input-output relations for particular variables. Moreover, the DEA assesses the efficiency analysis how, on average, the set of chosen inputs is transformed into the set of outputs and, as a result, the particular relation are not considered in this setting. Also note, that a fraction of type II errors is inevitable, as the power of the Moran's I test cannot be directly controlled.

Therefore, we allow spatially weighted inputs to positively affect outputs and, as a result, to increase the efficiency of healthcare systems within the investigated region. Hence, the spatial inputs are introduced into the denominator of the SDEA linear programming problem.

At the same time, we assume that a patient can travel from one region to the neighbouring region in search of medical assistance. In addition, patients may be treated away from their place of residence, although health statistics (including mortality) are assigned to the region where they live or die. As a result, the classic DEA may underestimate the effectiveness of healthcare in a given region because of the treatment of people from neighbouring regions; in these cases, some resources appear to be wasted because they do not produce a proportionate output in that region. To address this issue and to include medical services provided to non-residents in a given region, we expand the set of outputs by adding their values in neighbouring regions (spatial outputs).

Although the spatial patterns, clusters and significant spatial autocorrelation may be present, there is no direct causality, as all Western diseases incorporated in our example are non-infectious, and prevalence in one region cannot influence prevalence in another. As a result, no spatial output can be considered as an input. Thus, no spatial product inputs are reflected in the model. Notice, however, that if contagious diseases were 

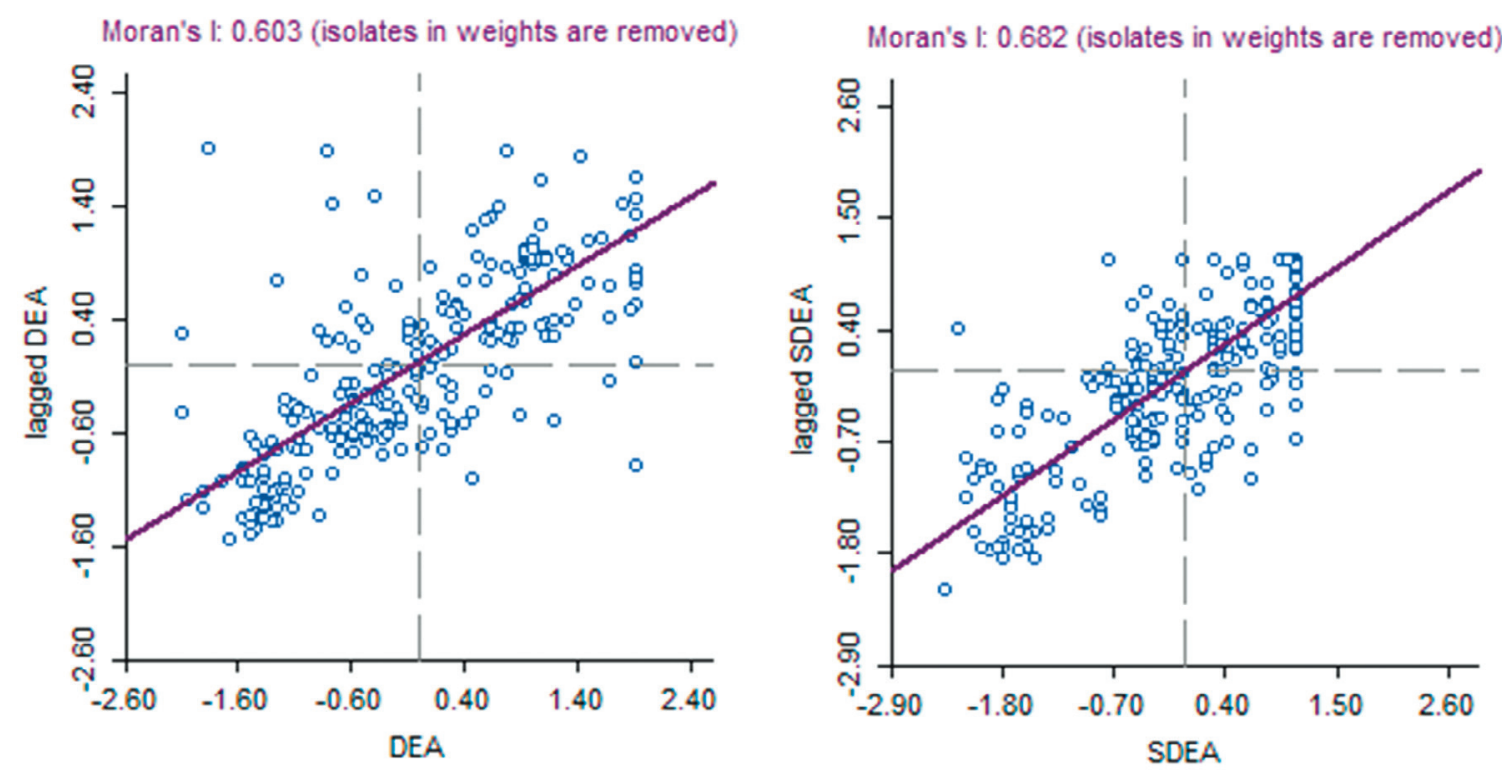

Fig. 2. Moran's I scatterplot for DEA and SDEA efficiency of healthcare systems, NUTS 2, 2013-2015

considered, causality would be present and consideration should be given to including some spatial product inputs in the healthcare model.

Summing up, in our application of SDEA to the efficiency of healthcare in NUTS 2 regions, we include both outputs Y and spatial outputs WY in the final set of outputs. Similarly, we incorporate inputs $\mathrm{X}$ as well as spatial inputs $\mathbf{W X}$ in into the ultimate set of inputs.

Figure 2 presents Moran's scatterplots, where spatial autocorrelation statistic is visualised as the slope of the regression line of the efficiency coefficient in neighbouring regions against the efficiency coefficient. For SDEA, the value of Moran's $\mathrm{I}=0.68$ ( $\mathrm{p}<0.001)$ confirms the spatial autocorrelation of the efficiency coefficient and indicates the possibility of its clustering and is higher than for DEA $(\mathrm{I}=0.60, \mathrm{p}<0.001)$. The more stringent SDEA framework emphasises inter-regional cooperation while demanding high performance not only from the region itself but also from its neighbours. As a result, SDEA highlights strong clusters while pulls less-performing regions down. Consequently, in this study, an increase in spatial autocorrelation of the efficiency coefficient in SDEA, as compared to DEA, confirms very strong cross-border relationships in healthcare efficiency through medical tourism and ongoing specialisation of healthcare facilities.

The results, presented in Figure 3, suggest that the overall spatial distribution of SDEA efficiency is similar to that of the classic DEA. Similarly, low-efficiency clusters are found in Germany, France, the Czech Republic, Austria, and Benelux, whereas high performance is observed in the Balkans, the United Kingdom, and the south- ern Iberian Peninsula. However, numerous additional effective regions can be observed in Poland, Greece, Italy, the Iberian Peninsula, the United Kingdom and Ireland. In general, efficiency levels are noticeably higher for the SDEA results compared with the results of the classic approach. To accurately assess the differences, additional analysis is necessary.

Comparing the DEA and SDEA results, we can observe that efficiency seems to be underestimated in the classic approach. Indeed, in the case of DEA, the lowest value of the efficiency coefficient is $33 \%$ for the Bratislava region (suggesting that $66.6 \%$ of inputs are wasted), whereas in the case of the SDEA results, the minimum value increases up to $52 \%$ in the case of Vienna. Second, the number of efficient regions has increased from 9 to 42 , that is, from $3.2 \%$ to $14.9 \%$ of the total number of regions. Finally, SDEA captured 34 (12.1\% of all regions) new Farrell efficient regions (all within the United Kingdom), which were not captured by DEA analysis. This means that for those regions, while the efficiency coefficient is equal to 1 (100\%), condition (b) in Definition 2 is not satisfied. Although proportional reduction of all inputs is not possible, changes for selected variables are required. This suggests that the classic DEA may incorrectly indicate that regions are inefficient because this solution underestimates the region-specific spatial context.

To accurately assess the differences between efficiency coefficients, we calculated the relative differences rate, which for region $r$ is defined as:

$$
D_{r}=\frac{\theta_{r}^{S D E A}-\theta_{r}^{D E A}}{\theta_{r}^{D E A}} 100 \% .
$$




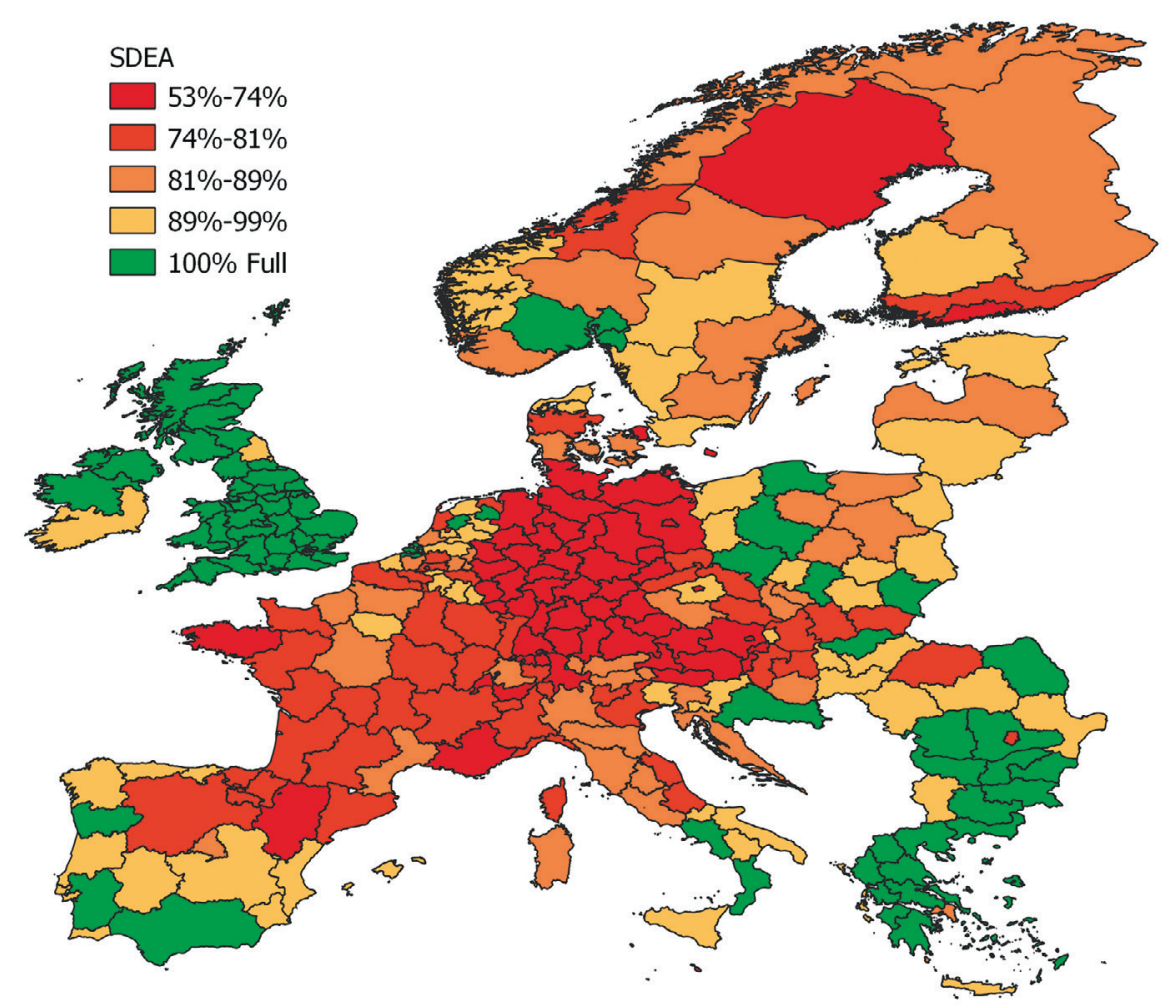

SDEA
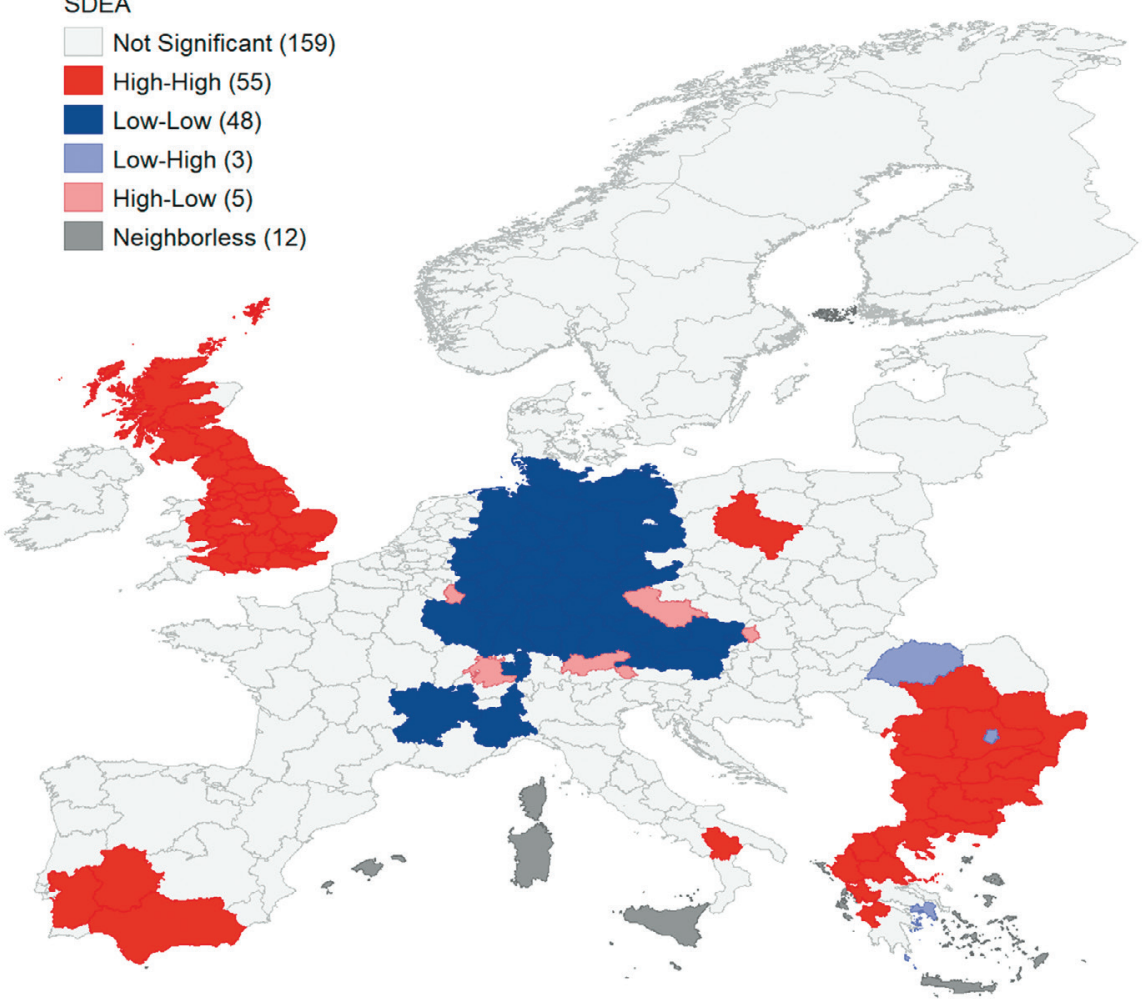

Fig. 3. SDEA efficiency coefficient and LISA analysis of healthcare systems, NUTS 2, 2013-2015, by deciles

The values of the relative difference rate are presented in Figure 4. First, for each region, SDEA coefficients are no lower than the corresponding DEA outcomes. The average increase in effectiveness per region is $27.3 \%$, with a $76 \%$ coefficient of variation. The highest increase is observed for the Bratislava region, which the classic DEA indicated as the least efficient region, with a $33.6 \%$ efficiency coefficient. In contrast, the spatial approach placed this region among those with the highest efficiency (93.7 \%). This suggests that the classical approach underestimated the performance of this region by as much as 60 percentage points, equivalent to a relative difference rate of $178.9 \%$. 

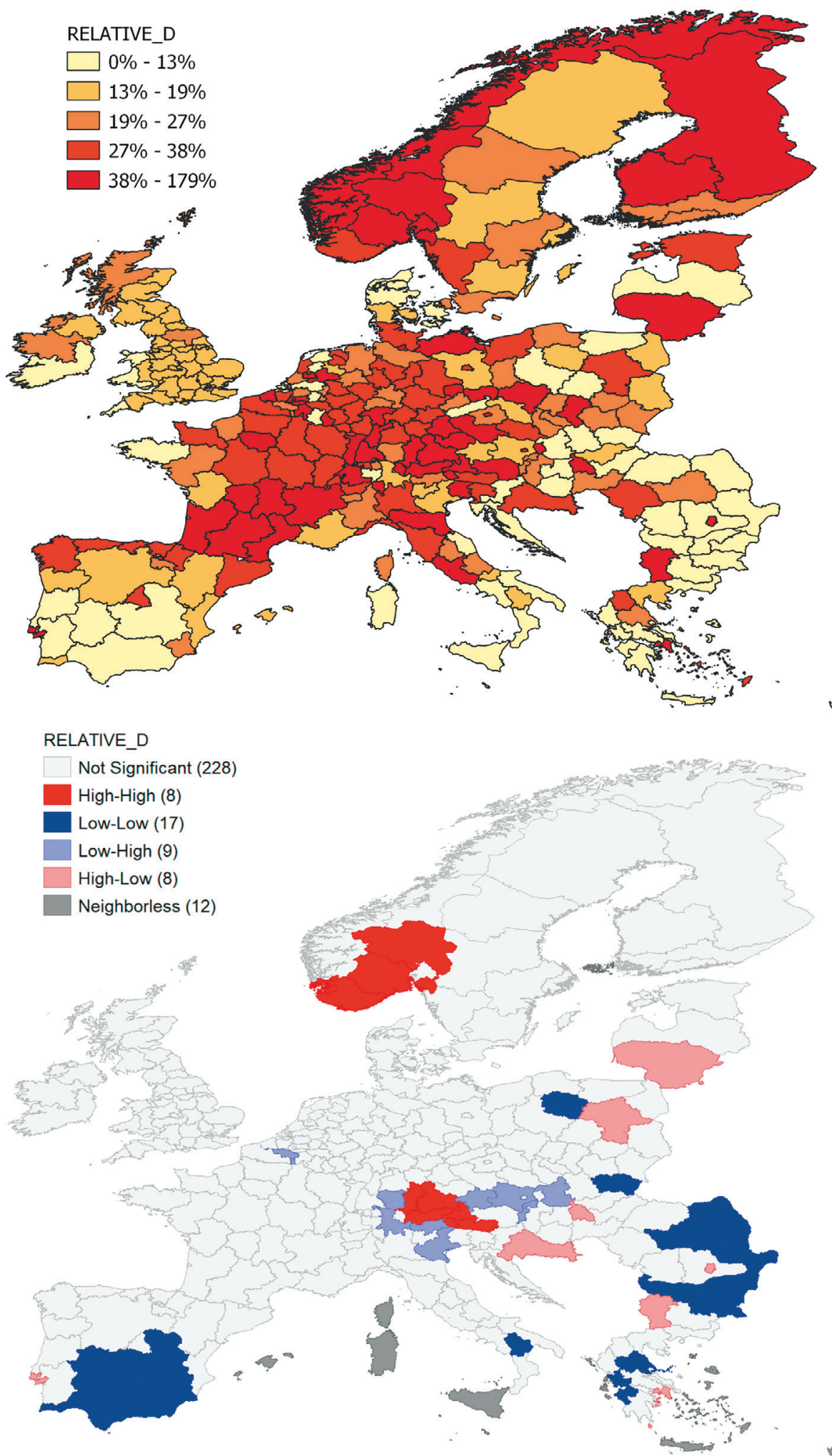

Fig. 4. Relative difference rate of healthcare efficiency coefficients for SDEA and DEA

The analysis of both spatial distribution and spatial association using the rate of the relative difference shows that there are no strong spatial patterns. The global autocorrelation is low but significant $(I=0.1, p=0.01)$ and the dispersion of the differences is high, which suggests that the overall correction in efficiency arising from SDEA results from region-specific factors. Only a few clusters exist. In fact, for highly efficient regions (according to both DEA and SDEA), which were located in the Iberian Peninsula and Balkans, the relative differences were small as proved by LISA cold- 
spots. On the other hand, in Western and Northern Europe, the relative differences between DEA and SDEA are much more substantial with some highhigh clusters. In these regions, the standard DEA underperformed the most, and therefore the correction of the spatial component is the largest.

\section{Conclusions}

In this paper, we introduce a modification of the classic DEA CCR model used in regional studies. A review of the literature on the efficiency of geographical units indicates that first, DEA and other methods based on the relative efficiency frontier are desirable. Second, the combination of DEA analysis with the spatial methodology of GIS and ESDA has become increasingly popular in recent years. This strongly suggests the need to explicitly include spatial interactions in the assessment of efficiency. Therefore, our modification is an attempt to extend DEA to its spatial form (i.e., SDEA) by including spatial interactions in parallel with classic input-output relations. Because some variables may not exhibit spatial patterns and because such patterns may vary, our modification allows an individualised approach to each variable (both inputs and outputs).

Our SDEA method has been used to assess the efficiency of healthcare in European NUTS 2 regions and compare it with the results of the classic DEA CCR model. Comparing the results of SDEA and DEA, we conclude that both approaches unanimously indicate that the efficiency of healthcare across Europe is very diverse and that few regions are fully effective. The analyses conducted indicate that DEA results in regional studies may underestimate the performance of some regions, as the classic approach does not properly consider the region-specific spatial context. Indeed, regions, unlike some other economic entities, are not independent and should not be treated as such in quantitative analysis. In the case of our study on healthcare, we show that ignoring the spatial spillovers of the production process reduces effi- ciency. One reason behind this is that inputs used in the production of outputs in neighbouring regions are considered wasted within a given region. As a result, the classic DEA approach underestimates the regional efficiency.

In general, it is not justifiable in regional settings to assume that the level variables (inputs and outputs) of the neighbouring regions do not affect the level of production in a given region. This is particularly the case if spatial exploratory analysis, which is used in our study, indicates the presence of spatial autocorrelation in the data. Thus, an adequate assessment of production efficiency calls for the inclusion of the spatial context through spatially lagged inputs and output. Although such phenomena are not present in our example study, we note that due to the interdependence of the production processes in neighbouring regions, it is possible for the classical DEA to overestimate efficiency if the spatial component is erroneously omitted in a study.

This paper presents both SDEA methodology and an example of its application. However, we are aware that there are some additional issues that should be addressed in future work. Indeed, further research must be done on how positive and/ or negative spatial autocorrelation influences the performance of the model. Moreover, the classic distinction between fully efficient and Farrell efficient regions may cause some interpretation problems. Therefore, it could be beneficial to design a slack-based measure that includes the spatial context. The results may potentially lead to more accurate assessments of levels of efficiency.

In the case of the healthcare efficiency example study, it would be useful to supplement the spatial analysis with dynamic analysis (e.g. Malmquist index of productivity). However, to do so, an annual standardised mortality rates (instead of the 3-year averages) would be preferable. Finally, more accurate prevalence statistics would also allow to improve and expand the assessment of regional healthcare efficiency.

\section{References}

1. Charnes, A., Cooper, W. \& Rhodes, A. (1978). Measuring the efficiency of decision-making units. European Journal of Operations Research, 2, 429-444.

2. Charnes, A., Cooper, W., Golany, W. \& Seinford, B. (1997). Data Envelopment Analysis. Theory, Methodology and Applications. Kluwer Academic Publishers.

3. Banker, R. D., Charnes, A. \& Cooper, W. (1984). Some models for estimating technical and scale inefficiencies in data envelopment analysis. Management Science, 30(9), 1078-1092.

4. Omrani, H., Shafaat, K. \& Emrouznejad, A. (2018). An integrated fuzzy clustering cooperative game data envelopment analysis model with application in hospital efficiency. Expert Systems With Applications, 114, 615-628. DOI: https://doi. org/10.1016/j.eswa.2018.07.074.

5. Giancotti, M., Rotundo, G., Pipitone, V. \& Mauro, M. (2018). Efficiency and optimal size of Italian public hospitals: results from data envelopment analysis. Epidemiology Biostatistics and Public Health, 15(4). DOI: 10.2427/12929. 
6. Aristovnik, A., Seljak, J. \& Mencinger, J. (2013). Relative efficiency of police directorates in Slovenia: A non-parametric analysis. Expert Systems with Applications, 40, 820-827. DOI: http://dx.doi.org/10.1016/j.eswa.2012.08.027.

7. Wua, T.-H., Chen, M.-S. \& Yeh, J.-Y. (2010). Measuring the performance of police forces in Taiwan using data envelopment analysis. Evaluation and Program Planning, 33(3), 246-254. DOI: 10.1016/j.evalprogplan.2009.09.001.

8. Żółtaszek, A. (2014). Leaders and followers in the effectiveness of public safety services in European states - a spatial frontier approach. Comparative Economic Research, 17(4), 253-272.

9. Mardani, A., Streimikiene, D., Balezentis, T., Saman, M. Z. M., Nor, K. M. \& Khoshnava, S. M. (2002). Data envelopment analysis in energy and environmental economics: An overview of the state-of-the-art and recent development trends. Energies, 11, 2002. DOI: 10.3390/en11082002.

10. Kourtit, K., Suzuki, S. \& Nijkamp, P. (2017). Tracing high-sustainability performers among world cities-design and application of a multi-temporal data envelopment analysis. Habitat International, 68, 43-54. DOI: 10.1016/j.habitatint.2017.06.011

11. Suzuki, S. \& Nijkamp, P. (2011). A stepwise projection data envelopment analysis for public transport operations in Japan. Tinbergen Institute Discussion Paper, TI 2011-113/3, 13.

12. Galinienè, B. \& Dzemydaite, G. (2012). Spatial data envelopment analysis method for the evaluation of regional infrastructure disparities. Social Technologies, 2(2), 390-403.

13. Shao, Y. \& Sun, C. (2016). Performance evaluation of China's air routes based on network data envelopment analysis approach. Journal of Air Transport Management, 55, 67-75.

14. Żółtaszek A. \& Pisarek R. (2016). Effectiveness of national airlines in Europe-the DEA approach. Folia Oeconomica Stetinensia, 16(2), 103-118.

15. Suzuki S., Nijkamp P. \& Rietveld, P. (2011). Regional efficiency improvement by means of data envelopment analysis through Euclidean distance minimization including fixed input factors: An application to tourist regions in Italy. Papers in Regional Science, 90(1), 67-89. DOI: 10.1111/j.1435-5957.2010.00316.

16. Gillen, D. \& Lall, A. (1997). Developing measures of airport productivity and performance: an application of data envelopment analysis. Transportation Research Part E: Logistics and Transportation Review, 33(4), 261-273.

17. Shao, Y. \& Sun, C. (2016). Performance evaluation of China's air routes based on network data envelopment analysis approach. Journal of Air Transport Management, 55, 67-75.

18. Dzemydaite, G. \& Galinienè, B. (2013). Evaluation of regional efficiency disparities by efficient frontier analysis. Ekonomika, 92(4), 21-36.

19. Athanassopoulos, A. D. (1996). Assessing the comparative spatial disadvantage (CSD) of regions in the European Union using non-radial data envelopment analysis methods. European Journal of Operational Research, 94, 439-452.

20. Wang, Z. \& Feng, C. (2015). Sources of production inefficiency and productivity growth in China: A global data envelopment analysis. Energy Economics, 49, 380-389.

21. Kapfer, M., Kantelhardt, J., Eckstein, K. \& Hübner, R. (2013). Environmental and economic impact of agricultural land use-a spatially explicit DEA approach. Working Paper 2nd AIEAA Conference "Between Crisis and Development: Which Role for the Bio-Economy", Associazione Italiana di Economia Agraria e Applicata, 18.

22. Lao, Y. \& Liu, L. (2009). Performance evaluation of bus lines with data envelopment analysis and geographic information systems. Computers, Environment and Urban Systems, 33, 247-255.

23. Almeida, G. E. S., Lee Ho, L., Giannotti, M. A. \& Quintanilha, J. A. (2013). Evaluation of the changes in the spatial distribution of companies in Osasco, (Sao Paulo, Brazil) by a data envelopment analysis (DEA). Revista Brasileira de Cartografia, 65(6), 1189-1198.

24. Kourtit, K. \& Nijkamp, P., (2013). In search of creative champions in high-tech spaces: A spatial application of strategic performance management. Journal of Regional Science, 53(5), 749-777.

25. Angeriz, A., McCombie, J. \& Roberts, M. (2006). Productivity, efficiency, and technological change in European union regional manufacturing: A data envelopment analysis approach. The Manchester School, 74(4 Special Issue), $500-525$.

26. Wang, Q., Jin, X. \& Zhou, Y. (2010). Efficiency socio-economic input factor of grain production based on DEA-ESDA. In: 2010 18th International Conference on Geoinformatics (pp.1-5). Beijing. DOI: 10.1109/GEOINFORMATICS.2010.5567959.

27. Mokaddem, L. (2015). Regions' efficiency and spatial disparities in Tunisia. In: Second International Conference on Advances In Management, Economics, and Social Science (MES) (pp. 207-216). Rome, Italy. DOI: 10.15224/978-1-63248046-0-131.

28. Schaffer, A., Simar, L. \& Rauland, J. (2011). Decomposing regional efficiency. Journal of Regional Science, 51(5), 931-947.

29. Maté-Sánchez-Val, M. L. \& Madrid-Guijarro, A. (2011). A spatial efficiency index proposal: An empirical application to SMEs productivity. The Annals of Regional Science, 47, 353-371. DOI: 10.1007/s00168-010-0382-8.

30. Anselin, L. (1988). Spatial Econometrics: Methods and Models. Kluwer Academic Publications, Dordrecht.

31. Żółtaszek A. \& Olejnik A. (2017). Regional effectiveness of innovation-leaders and followers of the EU NUTS 0 and NUTS 2 regions. Lodz Economics Working Papers 8/2017, University of Lodz, Faculty of Economics and Sociology, 28.

32. Olejnik, A. \& Żółtaszek, A. (2016). Spatial approach to diseases of affluence epidemiology and regional economic development. Folia Oeconomica Stetinensia, 16(2), 203-218.

33. Olejnik A. \& Żółtaszek, A. (2017). Spatial econometric approach to modelling of selected Western diseases. Folia Oeconomica, 6(332), 39-50. DOI: 10.18778/0208-6018.332.03. 
34. Żółtaszek, A. \& Olejnik A. (2017). Economic development and the spread of diseases of affluence in EU Regions. Folia Oeconomica, 5(331), 23-37. DOI: 10.18778/0208-6018.331.02.

35. Farrell, M. J. (1957). The measurement of productive efficiency. Journal of the Royal Statistical Society, Series A(III), 253-290.

36. Ravindran, A. R. (2016). Operations Research and Management Science Handbook. CRC Press: Boca Raton, Florida.

37. Anselin, L. (1995). Local Indicators of Spatial Association - LISA. Geographical Analysis, 27, 93-115.

38. Anselin, L., Syabri I. \& Smirnov O. (2002). Visualizing Multivariate Spatial Correlation with Dynamically Linked Windows. In: L. Anselin, S. Rey (Eds.), New Tools for Spatial Data Analysis: Proceedings of the Specialist Meeting. University of California, Santa Barbara: Center for Spatially Integrated Social Science (CSISS).

39. Danaei, G., Singh, G. M., Paciorek, K. J., Lin, J. K., Cowan M. J., Finucane, M. M., ... Ezzati, M. (2013). The global cardiovascular risk transition: Associations of four metabolic risk factors with macroeconomic variables in 1980 and 2008. Circulation, 127(14), 1493-1502. DOI: 10.1161/CIRCULATIONAHA.113.001470.

40. Farrell, C. (2010). Mental Disorders. ABDO Publishing Company: North Mankato, Minnesota.

41. Labarthe, D. (2011). Epidemiology and Prevention of Cardiovascular Diseases: A Global Challenge. Jones \& Bartlett Publishers: Sundbury, Massachusetts.

42. Link, K. (2007). Understanding New, Resurgent, and Resistant Diseases: How Man and Globalization Create and Spread Illness. Greenwood Publishing Group: Westport, London, 179.

43. Offer, A. (2006). The Challenge of Affluence: Self-Control and Well-Being in the United States and Britain Since 1950. Oxford University Press: Oxford.

\section{About the authors}

Alicja Olejnik - Department of Spatial Econometrics, Faculty of Economics and Sociology, University of Lodz (Lodz, Poland; e-mail: alicja.olejnik@uni.lodz.pl).

Agata Żółtaszek - Department of Spatial Econometrics, Faculty of Economics and Sociology, University of Lodz (Lodz, Poland; e-mail: agata.zoltaszek@uni.lodz.pl).

Jakub Olejnik - Department of Applied Computer Science, Faculty of Mathematics and Computer Science, University of Lodz (Lodz, Poland; e-mail: jakub.olejnik@wmii.uni.lodz.pl).

\section{Информация об авторах}

Олейник Алиси я - кафедра пространственной эконометрики, факультет экономики и социологии, Лодзинский университет (Польша, г. Лодзь; e-mail: alicja.olejnik@uni.lodz.pl).

Жулташек Агата - кафедра пространственной эконометрики, факультет экономики и социологии, Лодзинский университет (Польша, г. Лодзь; e-mail: agata.zoltaszek@uni.lodz.pl).

Олейник Якуб - кафедра прикладных компьютерных наук, факультет математики и информатики, Лодзинский университет (Польша, г. Лодзь; e-mail: jakub.olejnik@wmii.uni.lodz.pl).

Дата поступления рукописи: 12.11.2019.

Прошла рецензирование: 08.04.2020.

Принято решение о публикации: 24.09.2021.

Received: 12 Nov 2019.

Reviewed: 08 Apr 2020.

Accepted: 24 Sep 2021. 